\title{
An Improvement of Chalet Management System
}

\author{
Xue Ting Lim ${ }^{1}$ and Khai Loon Lee ${ }^{1, *}$ \\ ${ }^{1}$ Faculty of Industrial Management, Universiti Malaysia Pahang, 26300 Pahang, Malaysia.
}

\begin{abstract}
The constant growth of the tourism industry in Malaysia has led to the rise of the hospitality industry over recent years. The major tourism SMEs are usually providing the needs or demand of touristy to tourists such as food, accommodation, transportation and other necessities. This paper focuses on the issues of poor customer satisfaction and operational performance that occur in a small and medium scale hospitality company and the ways to solve the problem by developing a prototype of the Chalet Management System. The five whys analysis was used to identify the problems that occur in the hospitality company. The prototype of the Chalet Management System is developed by using Rapid Application Development (RAD) technique with Microsoft Access. This study showed that the Chalet Management System had improved customer satisfaction and operational performance by decreasing the registration process lead time and improving data accuracy and efficiency. The proposed system also received positive feedbacks with its functionalities from the company.
\end{abstract}

ARTICLE HISTORY

Received: 20-11-2020

Accepted: 04-01-2021

\section{KEYWORDS}

Chalet Management

System; Hospitality

Industry; Small and

Medium Enterprises

(SME); Customer

Satisfaction; Operation

Performance

\section{INTRODUCTION}

In Malaysia, the hospitality industry is blooming consistently with the uprising of the tourism industry in recent years. The hospitality industry also has been identified as one of the major contributors to the national economy as the hospitality industry covers a wide range of organizations offering food service and accommodation. This industry is unique because it involves people that are being served by people and tends to be service-oriented. The hospitality industry can consider as successful sector nowadays and many of the customers are focusing on the service quality.

Technological revolution brought a huge impact around the world as it promotes the usage of advanced technology. The growth of information and communication technology (ICT) provides an extreme effect on the industry including the hospitality industry (Khan \& Hossain, 2018). It causes the hospitality industry to face each other competitively in order to meet customer expectations. Therefore, lots of the hospitality industry are replacing their manual management system and moves towards the computerized system in order to achieve customer expectations (Guo \& Lu, 2014). However, there were few companies especially the small and medium enterprise does not have enough budget to implement this technology system in helping them to manage the company (Mohd Sallem, Mohd Nasir, Wan Mohd Nori, \& Che Ku Kassim, 2017).

ABC chalet is a hospitality industry that under the SME section which was established in 1997. ABC chalet based in a rural tourism area which is located at Kukup, Johor. ABC chalet now has 11 units of chalet, 30 units of hotel room and incoming 2 units of vacation homes that are managed by approximately 10 staff. According to the Domestic Tourism Survey 2018, the number of domestic tours shows a double-digit growth of $10.9 \%$ in 2018 which recorded a total number of 78.2 million domestic tourists compared to 70.5 million domestic tourists in 2017 ("Domestic Tourism Performance 2018 - Tourism Malaysia Corporate Site," 2019). The expanding growth for the domestic tours has helped in the increasing number of visitors around $25 \%$ from the year 2017 to 2018 to the ABC chalet. However, ABC chalet is still facing a problem that requires attention to be solved immediately due to the increasing numbers of visitors. This study will focus on the problems faced by $\mathrm{ABC}$ chalet and propose a possible solution.

\section{RESEARCH PROBLEMS}

Customer satisfaction is applied commonly for the hospitality industry to gain a competitive advantage over the past decades. Customer satisfaction is a crucial factor to run a successful business, especially in the hospitality industry. The hospitality industry focuses on services related to leisure and customer satisfaction. Customer satisfaction is directly proportional to the timeliness of customer service (Watiki \& Chirchir, 2014). The timeliness of customer service is measurable by the registration process lead time where it occurs at the reception counter of the industry. This registration process lead time is mainly controlled by the data accuracy and efficiency of a system can be provided. For example, a manual customer handling system is having a lower data accuracy and efficiency than an automated customer management system as human need to interpret the correct information by eyes without even excluding the possibility of human error occurred. This will cause the registration process lead time at each reception counter to be longer than before and lowers the timeliness of customer service. Therefore, many hospitality industries such as $\mathrm{ABC}$ chalet faced the 
difficulties of satisfying their customers and ended up with poor customer satisfaction when they are using a manual customer handling system at their reception counter. This also results in the declining image of the industry and thus the amount of customers reservation might be affected (Chen \& Tabari, 2017). Therefore, a study is required to be conducted on the problem of poor customer satisfaction and resolved as customer satisfaction and good service provided are key factors for $\mathrm{ABC}$ chalet to gain a competitive advantage that will attract new customers and retain them. This can be investigated by collecting their customer feedbacks and staff suggestions and a solution can be proposed based on these..

\section{RESEARCH QUESTIONS}

This research has questions on hospitality company listed as below:

1. What are the factors affecting poor customer satisfaction in $\mathrm{ABC}$ chalet?

2. How to enhance the registration process lead time of $\mathrm{ABC}$ chalet?

3. How to improve data accuracy and efficiency of the customer database of ABC chalet?

\section{RESEARCH OBJECTIVES}

The objectives of this study are:

1. To investigate the factors affecting poor customer satisfaction in ABC Chalet.

2. To enhance the registration process lead time of ABC Chalet by a prototype of Chalet Management System.

3. To improve customer's data accuracy and efficiency of ABC Chalet by a prototype of Chalet Management System.

\section{SCOPE OF STUDY}

This study will be focusing on developing a prototype of Chalet Management System and how this prototype can help ABC chalet to improve data accuracy and efficiency which can improve their timeliness of customer service. This will lead to the changes in the duration of registration process lead time at their reception counter and thus affect their customer satisfaction. ABC chalet is selected as it is a small-scale hospitality firm from a rural tourism area where it is suitable for both implementation and investigation. There, the collections of customer feedbacks and staff suggestions are required for designing the system requirements of the prototype.

\section{SIGNIFICANCE OF STUDY}

This study provides a prototype of Chalet Management System to replace the handwritten record of the customer details to ABC chalet. The developed prototype will be assisting the staff in minimizing the lead time of the registration process. The registration process lead time can be decreased by just entering keywords of the customer details. Besides, the system can help to improve data accuracy that allows the staff to check the availability of rooms and reserve the available rooms for respective customers. The entire process in the front desk can help to increase customer satisfaction as reducing the customer waiting time through the aid of the system.

\section{LITERATURE REVIEW}

\section{Why-Why Analysis}

The five why analysis is referring to the Toyota Production System (TPS). Taiichi Ohno described the method by asking the "why" 5 times when finding a problem and the solution will become clear (Card, 2016). It is a method that is used for searching for the root cause of a problem. Rather than taking actions that are merely Band-Aids, a why-why helps you to identify how to really prevent the issue from recurring again and again (Hassan \& Jalalud, 2016). This method is suitable to find out the root cause of why ABC chalet is having poor customer satisfaction with their existing management of the reception counter. It is also excellent for collecting the requirements of the system design for the prototype of Chalet Management System.

\section{Rapid Application Development (RAD)}

According to Martin (1995), one can achieve faster and higher quality results through Rapid Application Development (RAD) which is a lifecycle development than those achieved with the traditional lifecycle. RAD is a type of incremental model which all the components or functions are developed in parallel as they were segmented into small projects. There are four main phases in RAD which are requirement planning, user design, construction, and cutover (Beynon-Davies \& Holmes, 2002). Nowadays, RAD is popular because it creates software that can quickly adapt to market and customer requirements by using a shorter development time. The advantages of proposing a system to be built with RAD is it can be easier to build, the increase of reusability for components, occurrence of quick initial reviews and reducing integration issues as the integration started from the beginning of a development. The high decision making of RAD model can increase accuracy and quality of data as it helps in measuring the progress accurately, quickly and reducing the progress 
time (Fatimah, Supriatna, \& Kurniawati, 2018). Hence, the prototype of Chalet Management System for ABC chalet will be built with RAD structure.

\section{Searching Speed}

In Malaysia, most of the small and medium enterprise (SME) are still using the manual documenting system. This is because SME such as ABC chalet has an only limited budget and cannot afford to buy an enterprise-level system for operation in the company such as ERP, SAP. Thus, handwriting records are used in order to keep the customer details and this had affected the data efficiency as this required the reception staff to take longer time in searching the exact customer data. Even if these handwritten records are already sorted and well-documented, the staff of ABC chalet still needed time to trace back the matching records and human errors can still happen in the handwriting (Abidin \& Husin, 2018) which decrease the data accuracy.

\section{Waiting Time}

As the growth of customer expectations nowadays, it is significantly important for the hospitality industry especially chalet or hotel has a reliable front desk management. Front desk management is the first and the last area that is visited by customers. Therefore, the reception counter is responsible for numerous functions such as customer enquiries, room registration and reservation of guests, coordinating room services, gain guests feedback and collect payment. A seamless service should be provided at the front desk management and this can enhance customer satisfaction as a good first impression is already given to the customer. The registration process lead time that provided at the reception counter is affecting customer satisfaction as customer waiting time also get longer when the lead time gets longer. If the wait time is short, the customer will feel that the quality of service is good enough. On the contrary, while the waiting time is longer, the customer will also think that the service quality is poor, affecting customer satisfaction (Alsumait, 2015). There, the customer service process delivered in front desk management will impact customer satisfaction.

\section{Customers Satisfaction}

Based on the customer satisfaction model developed (Oliver, 1981; Mmutle \& Shonhe, 2017), satisfaction is generated when customers compare their perception of the performance of an actual product or service with their expectations. According to (Jana \& Chandra, 2016), customer satisfaction has become a crucial factor in the hospitality industry. Achieving customer satisfaction in the hospitality industry will be considered as the foundation and expansion of the business. Customer loyalty is always depending on the service quality that is provided by a particular hospitality industry (Mubiri, 2016). Higher customer satisfaction will lead to customer loyalty by delivering good service quality. Service quality is also another important factor in the hospitality industry. Attitudes, beliefs and actions delivered by staff in the hospitality industry will give significant impact towards service quality and then influence customer satisfaction. A good service quantity will help the hospitality industry to obtain a sustainable competitive advantage too. Unsatisfied customers are more likely to find the chance to publish poor service and discourage others to have the same service. On the flip side, happy customers are always willing to recommend the place with good service to their friends or families. Therefore, it is important to recognize customers' needs and able to satisfy them in order to achieve customer satisfaction. Customers will look forward to another competitor if they are not satisfied (Jana \& Chandra, 2016). If the product or services level is better than the customer's expectations, customer satisfaction will be more likely to be achieved (Ankur, 2018).

\section{THE CASE COMPANY}

\section{Company Background}

Kukup is a small fishing village which is located in Pontian District, Johor. This fishing village already exists over 100 years and is built on above the muddy mangrove shoreline. In the 1990s, the development of the travel industry in Kukup had begun and this caused the village to become the Southern sea fishing village which has the delicious seafood and the popular sightseeing tourist place in Asia. Therefore, many floating resorts were built and formed in Kukup.

$\mathrm{ABC}$ chalet is one of the small floating resorts that provides hospitality services to travellers in Kampung Air Masin, Kukup, Johor. This chalet started their guesthouse business in 1997. The guesthouse was built of wooden blocks and first started with only three units. In 2014, the company expanded its business and renovates the guesthouse completely. The company replaced the wooden chalets with bricks and steels. The company was the first resort to have both hotels and chalets facilities with a total land size of $105 \times 300$ feet. The operating hours of the resort start from 7.00 a.m.-11.00 p.m. daily. The resort is usually fully booked on most Saturdays, Sundays and public holidays. Currently, the resort has 11 units of chalet services and 30 units of hotel room services with upcoming 2 units of Airbnb services. Each of the tenants from chalet services and hotel service will be provided 4 meals for one-night stay package except tenants from the Airbnb services.

\section{RESEARCH METHODOLOGY}

The 5-Whys technique had been chosen to identify the root cause of the customer dissatisfaction issues happened in the selected hospitality firm. A series of Five-Whys questions formed a query process that helps to identify the potential causes (Chemweno et al., 2016). 
For this study, the method of Rapid Applications Development (RAD) have been chosen to solve the problems that are found by the Five-Whys technique by using Microsoft Access. RAD is focusing on prototyping to produce software applications with graphical user interface design. With RAD and Microsoft Access, the software will not require a long time to develop and allow the user to test the system. Therefore, any new function or fixing can be adapted by this software easily according to user suggestions and comments. Microsoft Access provides the benefit of minimizing the duplicates of data and make the user can insert the data easier and faster. Besides that, this will be able to overcome the issues faced by using a manual system by providing a more cost-effective and high time efficiency reservation process for the user.

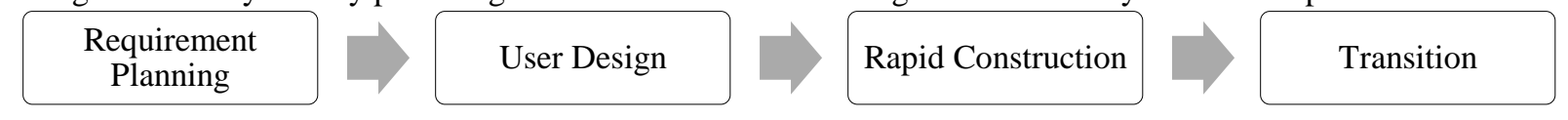

Figure 1. Four Main Phases in RAD.

Figure 1 showed the four main phases in RAD which are requirement planning, user design, rapid construction, and transition. In the requirement planning phase, a general understanding of business problems for the development needs to be collected through discussion with the stakeholder and their approvals. The user design phase is an interactive process between users and system analyst to develop the models that represent all system processes, outputs, and inputs. The application coding, testing and integration will take place in the rapid construction phase. It focused on program and application development. The transition phase also called as cutover that included the data conversion, testing, changeover to the new system, and user training. A Chalet Management System will be developed to help in solving the problems stated and allow users to visualize the final solution.

\section{RESULT AND DISCUSSION}

\section{Why-why Analysis}

Five Whys' analysis has been carried out to find out the issues that have been faced by the company. The results of the analysis showed as below:

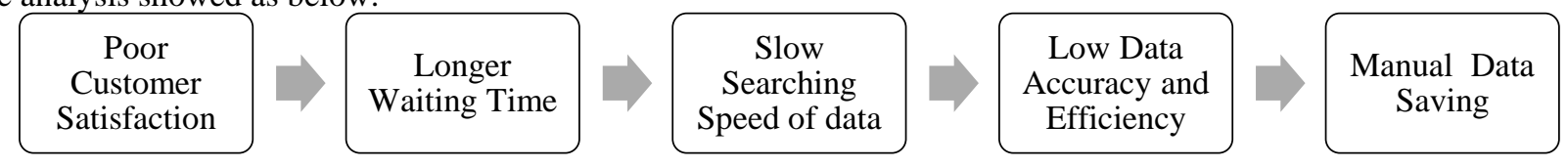

Figure 2. Five-Whys' Analysis.

The causes of poor customer satisfaction were identified after collecting some feedback from their customers. First, customers always complain that they were needed to wait for a long time to complete their registration process while checking in their room as this registration process require the staff to trace back the reservations recorded on a logbook and verified it by eyeball. Then, the staff had to write down the check-in details and verified the payment amount to be collected carefully. If the reservation was made for a chalet unit, the group of guests have to wait together before completing the registration as the key can only be given after that. If there were three different groups of guests arrived on the same time, the staffs need to make ad-hoc arrangements to send out the latest arrival batch for other activities such as visiting Pulau Kukup instead of having them to wait for a long time due to registration process of the first arrival group. This was why $\mathrm{ABC}$ chalet is encountering the customer dissatisfaction as the slow service quality in the registration process. This issue also rose due to the factors of the slow searching speed of customers details since the customer's details are just handwritten record that kept in separate files. Staff also found it troublesome as they have to dig out the correct the exact customer details before passing them the chalet key or hotel key to the customer. In the meantime, they were also stressful to keep their customer waiting.

\section{Rapid Applications Development (RAD)}

A prototype of Rapid Applications Development (RAD) has been developed to solve the issue that are found in the reception counter of $\mathrm{ABC}$ chalet. The 4 important steps of developing the prototype of RAD is discussed. The requirement planning of $\mathrm{ABC}$ chalet is to develop the interface for reception counter that can enhance the registration process of the customers by improving the searching speed of customer data and the availability of rooms. In the step of user design, the prototype of RAD is developed according to the requirement of $\mathrm{ABC}$ chalet. Figure 3 showed the Entity-Relationship Diagram of ABC chalet. 


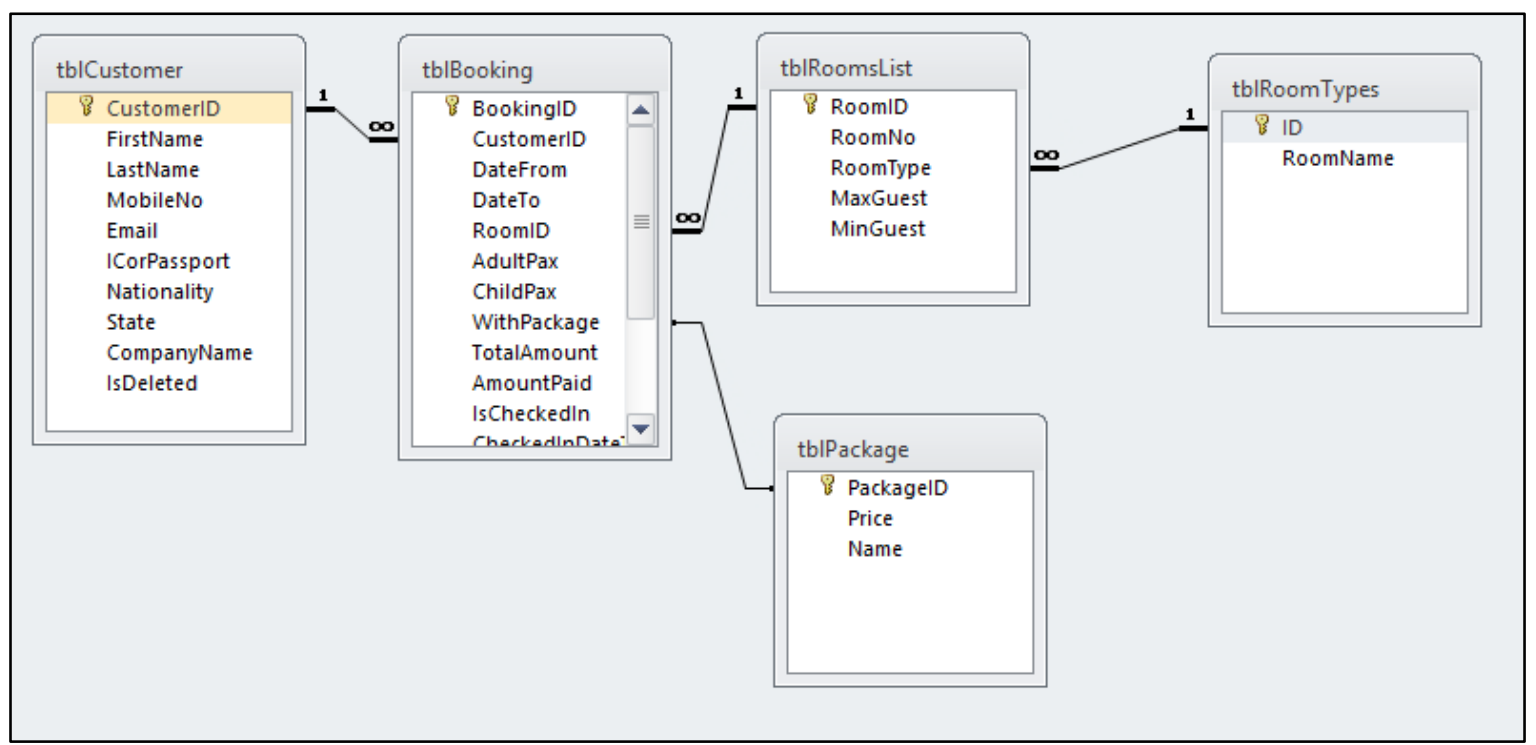

Figure 3. Entity-Relationship Diagram (ERD).

The third step is the rapid construction phase which is the development of the prototype. The last step of RAD is the transition phase which is the final result of the prototype for this study that includes the testing, conversion, and user training. Each of the interfaces of the system is explained as detailed.

Figure 4 showed the interface to create a new customer record. After the manager received the reservation order from the customer by phone or social media tools such as Facebook or Whatapps, the details of the customer can be will be recorded with this interface. The address of customers is not recorded as the management of $\mathrm{ABC}$ chalet confirmed that the collection of customer address is unnecessary as NRIC or passport number is already collected for tracing if required.

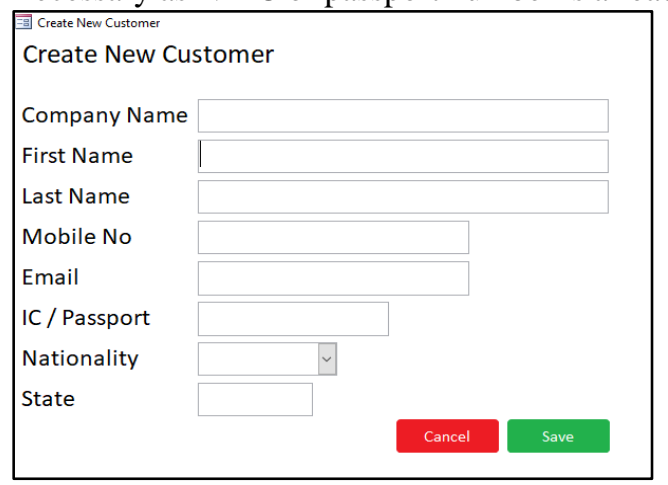

Figure 4. The interface of Create New Customer.

Next, the staff can go to the interface of the select customer and create a new booking for the specific customer. A search bar is available for searching by typing the customer name or NRIC number. Figure 5 showed the interface to select customers.

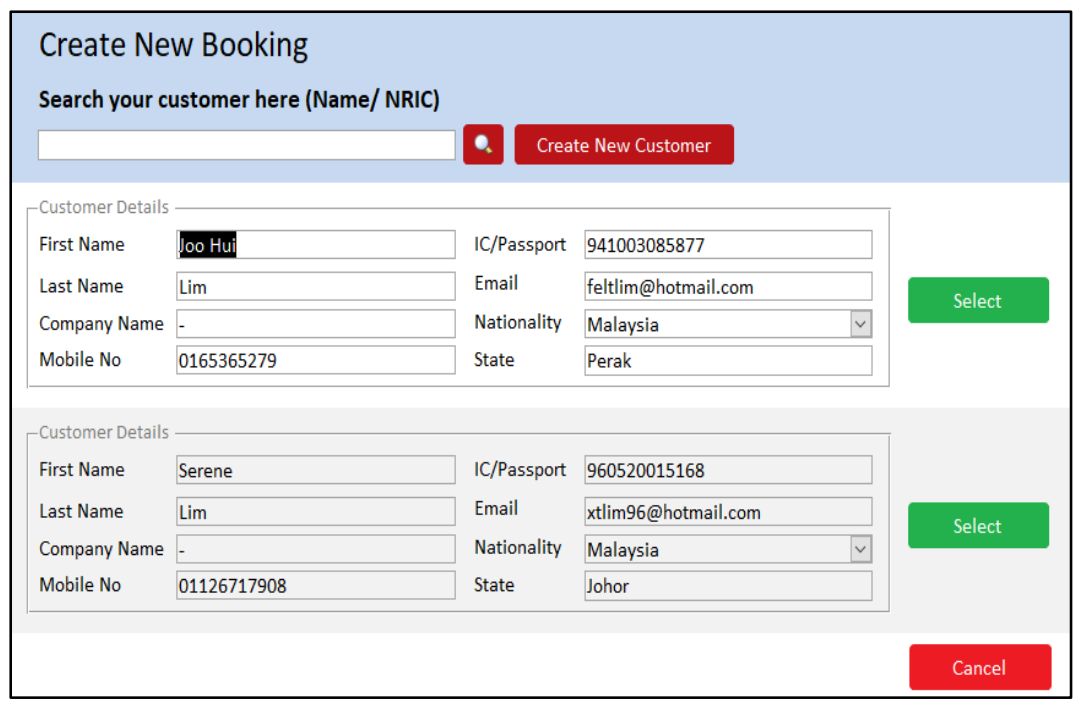

Figure 5. Interface of Create New Customer. 
In the interface of creating a new booking, the staff should select the visiting dates and number of pax including adult and child and click the search button to search the available room on the selected dates. Next, the staff have to select the room type which is a hotel or chalet according to a customer enquiry. Then, the list of room available will be popped up on the dropdown of the Room Available. The room number for the chalet is starting with the number of " $1,2,3$ until 11" while the room no for the hotel starts with the number of " $021,022,023$ until 0231 ". The staff just have to verify the room selected is suitable for the total number of pax visiting. The package is available with two options "Yes" and "No" is required to be selected as the pricing will be different as this package will be providing four meals for guests within the stay. The pricing is also different for adult and child for chalet reservation whereas the pricing will be standard for hotel reservation without package included at max 2 guests per room. For the last step, click the Add button and a new reservation record will be made and updated to the database and this new reservation will appear under the booking form for preview. When the staff are done to create a new booking, they can click the Finish button to navigate back to the home page. Figure 6 showed the interface to create a new booking.

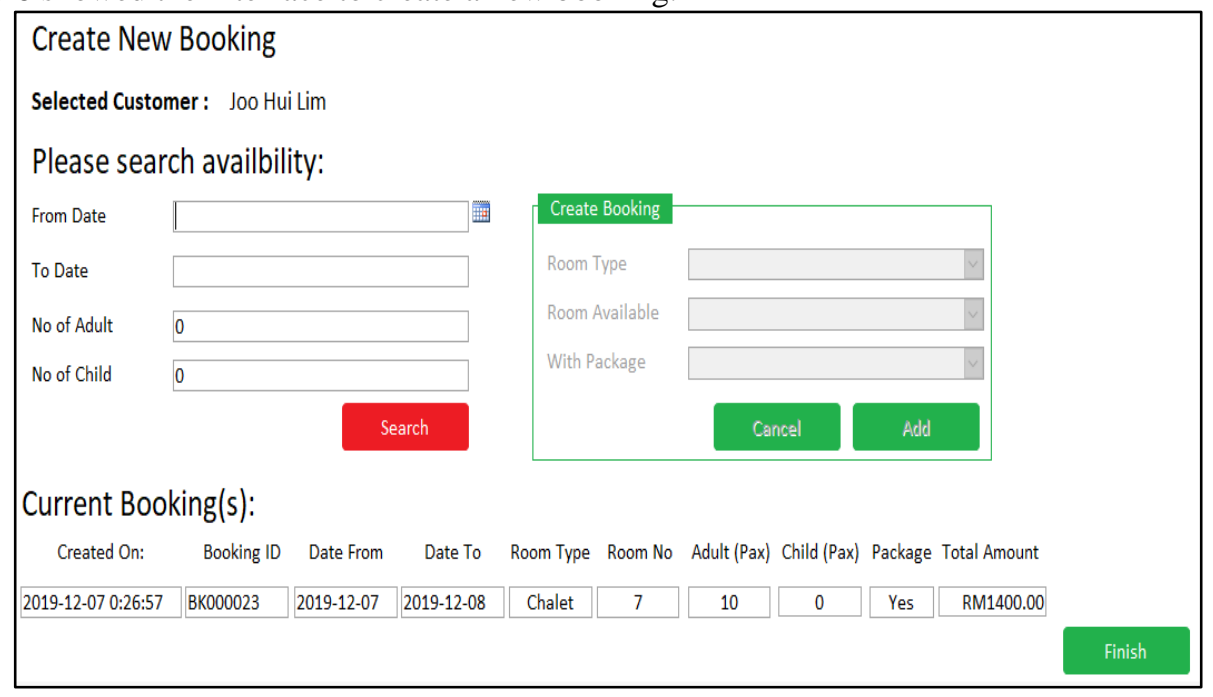

Figure 6. Interface for Create New Booking.

Figure 7 showed the check-in interface for daily incoming customers. This interface is also one of the tab pages of the system. When the customers arrive at ABC Chalet, the staff can find the booking record by searching with the name or NRIC or passport number of the registered customer on the search bar. The details for the specific customers can be traced easily and it also stated the total amount to be paid by the customers. The staff can click the check-in button and print the invoice report to the customers once the customer made the full payment. If the customer is not managed to make the full payment in registration, the staff can still proceed them to check-in while the amount of payment collected will be updated according to the window popped up. However, the invoice cannot be generated at the moment as the payment is not fully made. This check-in process is time effective and shorter than the previous manual handling system.

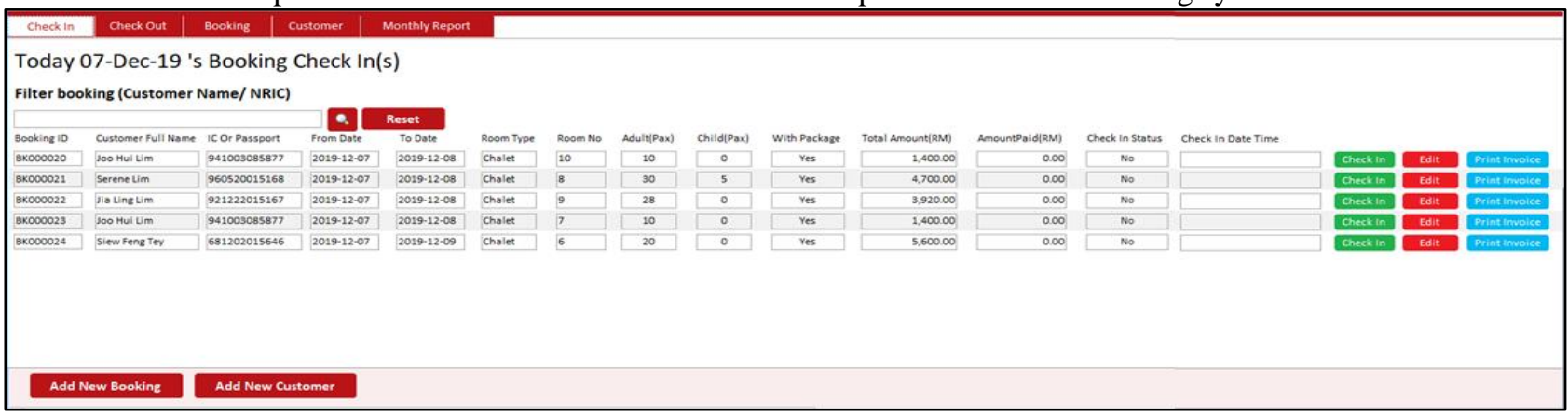

Figure 7. Check-in Interface for Customers.

Figure 8 showed the check-out interface for daily checkout customers. Staff can check out guests that were already finishing their stay easily when they approach the reception counter. By typing the customer name or NRIC number on the search bar, the staff can trace the record of the visit and perform the check out by clicking the "Check Out" button. If the payment was not fully made, a window will prompt to staff to alert the collection of payment. The payment can be updated by clicking the "Edit" button. The invoice report for the respective stay can be generated and given to the customer after clicking "Print Invoice" button. This shows that this check out process is seamless to both customer and staff compared to the previous manual handling system. 


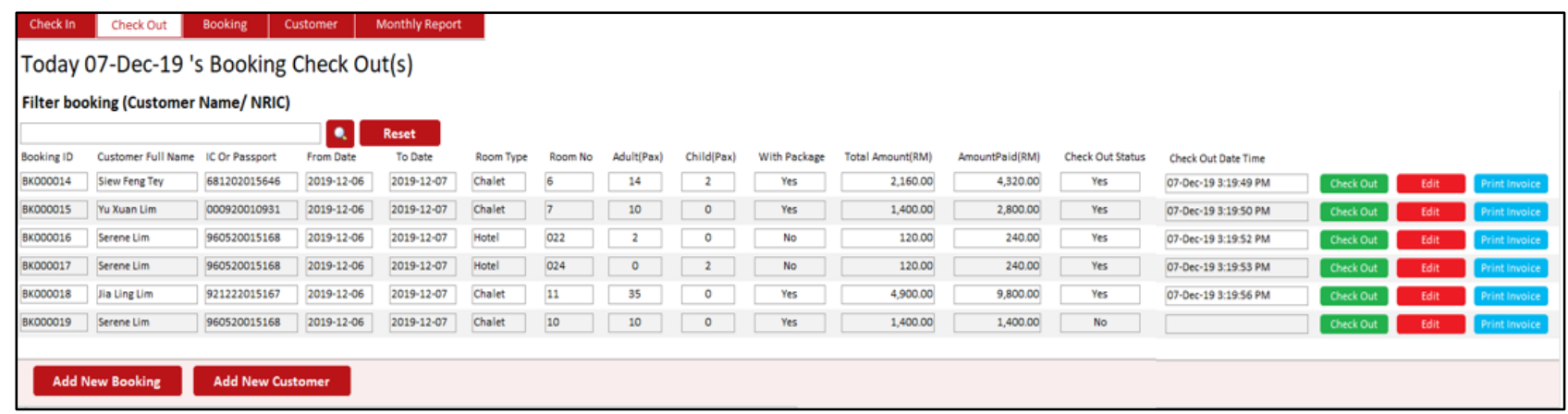

Figure 8. Check-out Interface for Customer.

Figure 9 showed a sample of an invoice to be printed and given to the customer. The invoice can be generated immediately by the automated system and all related information will be displayed on the invoice.

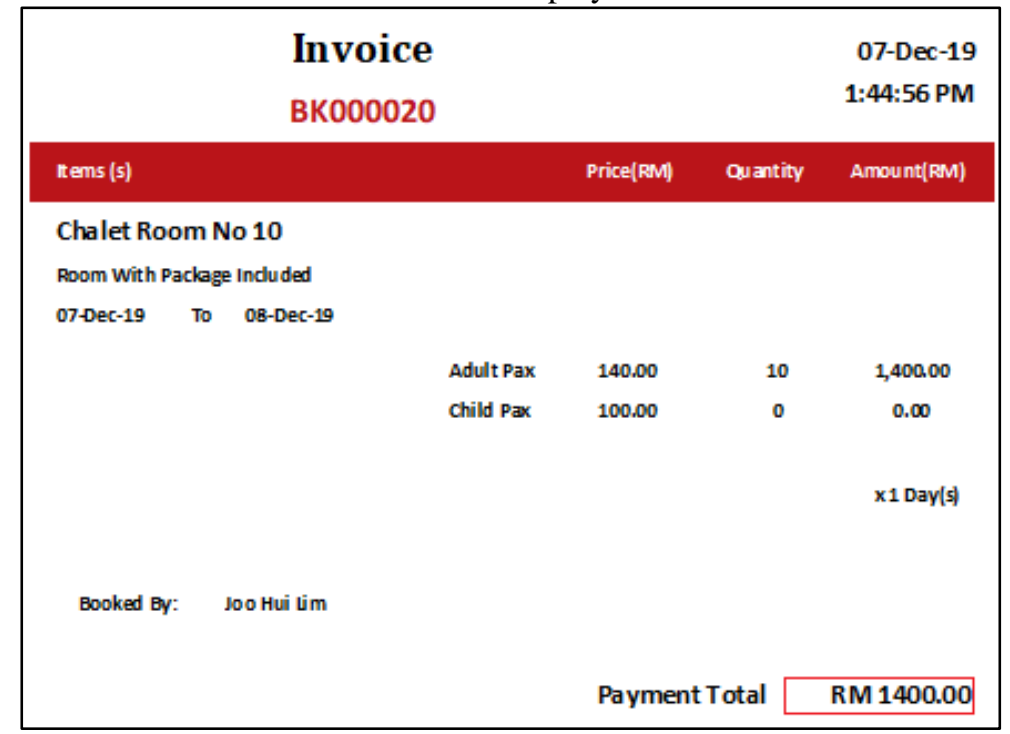

Figure 9. Invoice Report.

Figure 10 showed the interface of the report. The report can be generated immediately by the automated system by just filling the range of date.

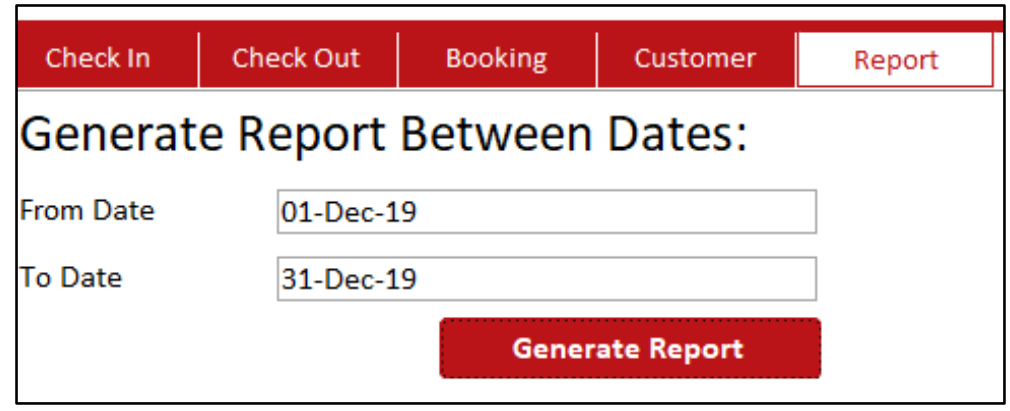

Figure 10. Report Interface.

\section{Time Study}

Time Study and Methods Engineering (Analysis) was used to measure the registration process lead time in the ABC chalet. Three sets of readings were taken recorded in the corresponding column respectively and the average of the time readings will be calculated to achieve a more accurate result. The actual time of using manual record file and the demo time of Chalet Management System for the registration process in the front desk is compared. Table 1 and Table 2 showed the comparison of time during the customer registration process among the current manual system and the prototype of Chalet Management System.

Time study of Table 5.1 and Table 5.2 has proved that the user of the prototype of Rapid Applications Development (RAD) can help ABC chalet in reducing the registration lead time. From Table 5.1, it can be observed that the total cycle time of the registration process for the customers who had reserved earlier by phone or WhatsApp is decreasing from 13 minutes to 6 minutes. It can be saved about $52 \%$ of time registration by using the prototype of Chalet Management System. The time for finding the customers data has been reduced from 372s to 31s. From the result that showed in Table 5.2, the prototype of Chalet Management System had speed up the registration process lead time for those walk-in 
customers around 5 minutes and saves $38 \%$ of their time compared to the current manual record. Some of the processes by using manual such as calculate the payment and write the receipt in a manual receipt book has been eliminated as the system is capable to generate the invoice automatically on each booking and it helped in saving time too. Thus, the poor customer satisfaction can be solved as the registration process time is shorter and these customers are no longer required to wait for a certain amount of time and thus, they can save up their time to begin their vacation.

Table 1. Comparison of Time Study for the Customers that Reserved Earlier among Manual Record and Chalet Management System.

\begin{tabular}{|c|c|c|c|c|c|c|c|c|}
\hline \multirow[b]{2}{*}{$\begin{array}{l}\text { Customer Check-in } \\
\text { (Reserved Earlier) }\end{array}$} & \multicolumn{4}{|c|}{ Current Cycle Time (sec) } & \multicolumn{4}{|c|}{ By using RAD } \\
\hline & Data 1 & Data 2 & Data 3 & Average & Data 1 & Data 2 & Data 3 & Average \\
\hline Greeding to Customer & 80 & 90 & 105 & 92 & 80 & 90 & 105 & 92 \\
\hline $\begin{array}{l}\text { Request Customer IC and their Mobile } \\
\text { No }\end{array}$ & 28 & 45 & 30 & 34 & 28 & 45 & 30 & 34 \\
\hline Find the Customer Data & 350 & 379 & 388 & 372 & 27 & 35 & 32 & 31 \\
\hline Confirm the details with customers & 20 & 23 & 26 & 23 & 20 & 23 & 26 & 23 \\
\hline Edit the details of customer & 53 & 40 & 38 & 44 & 27 & 32 & 33 & 31 \\
\hline $\begin{array}{l}\text { Calculate the total payment based on } \\
\text { customer details }\end{array}$ & 15 & 20 & 10 & 15 & & & & \\
\hline Collect the cash from customer & 110 & 90 & 120 & 107 & 110 & 90 & 120 & 107 \\
\hline $\begin{array}{l}\text { Write the receipt with a manual receipt } \\
\text { book }\end{array}$ & 38 & 30 & 35 & 34 & & & & \\
\hline $\begin{array}{l}\text { Give the Room Key and Receipt to } \\
\text { Customer }\end{array}$ & 55 & 57 & 60 & 57 & 55 & 57 & 60 & 57 \\
\hline Total cycle time (second) & & & & 778 & & & & 375 \\
\hline Total cycle time (minute) & & & & 13 & & & & 6 \\
\hline Saving & & & & & & & & $-52 \%$ \\
\hline
\end{tabular}

Table 2. Comparison of Time Study for the Walk-in Customers among Manual Record and Chalet Management System.

\begin{tabular}{|c|c|c|c|c|c|c|c|c|}
\hline \multirow[b]{2}{*}{ Customer Check in (Walk-In Customer) } & \multicolumn{4}{|c|}{ Current Cycle Time (sec) } & \multicolumn{4}{|c|}{ By using RAD } \\
\hline & Data 1 & Data 2 & Data 3 & Average & Data 1 & Data 2 & Data 3 & Average \\
\hline Greeting to Customer & 80 & 90 & 105 & 92 & 80 & 90 & 105 & 92 \\
\hline Check the availability of room & 178 & 165 & 124 & 156 & 45 & 43 & 41 & 43 \\
\hline $\begin{array}{l}\text { Request Customer IC and their Mobile } \\
\text { No }\end{array}$ & 28 & 45 & 30 & 34 & 28 & 45 & 30 & 34 \\
\hline Record the Customer Data & 135 & 147 & 123 & 135 & 62 & 55 & 48 & 55 \\
\hline $\begin{array}{l}\text { Calculate the total payment based on } \\
\text { customer details }\end{array}$ & 15 & 20 & 10 & 15 & & & & \\
\hline Collect the cash from customer & 110 & 90 & 120 & 107 & 110 & 90 & 120 & 107 \\
\hline $\begin{array}{l}\text { Write the receipt with a manual receipt } \\
\text { book }\end{array}$ & 38 & 30 & 35 & 34 & & & & \\
\hline $\begin{array}{l}\text { Give the Room Key and Receipt to } \\
\text { Customer }\end{array}$ & 55 & 57 & 60 & 57 & 55 & 57 & 60 & 57 \\
\hline Total cycle time (second) & & & & 630 & & & & 388 \\
\hline Total cycle time (minute) & & & & 11 & & & & 6 \\
\hline Saving & & & & & & & & $-38 \%$ \\
\hline
\end{tabular}

\section{Data Accuracy and Efficiency}

The prototype of Chalet Management System provided the search function in the check-in, check out the interface, customers interface and booking interface which can help the staff to track the customer data more efficiently. This function has increased the data accuracy and efficiency for the staff to obtain the exact customer data as every customer record was being recorded in the database. The issue of room assignment whereby a room was already occupied but ended assigned again to another guest due to human error from the staff was avoided significantly. This was because the system will automate the calculation of room availability before allowing the user to select the room for each booking. It helped to resolve the frustration of staff and guests as it prevents them from facing the previous problem such as when the customer arrived but ended swapping another room due to room was already occupied by other customers. This problem had caused low customer satisfaction during the swapping of the room also requires time and effort to move luggage from one room to another room for the customer. Figure 11 showed the sample of the searching engine of customer name. 


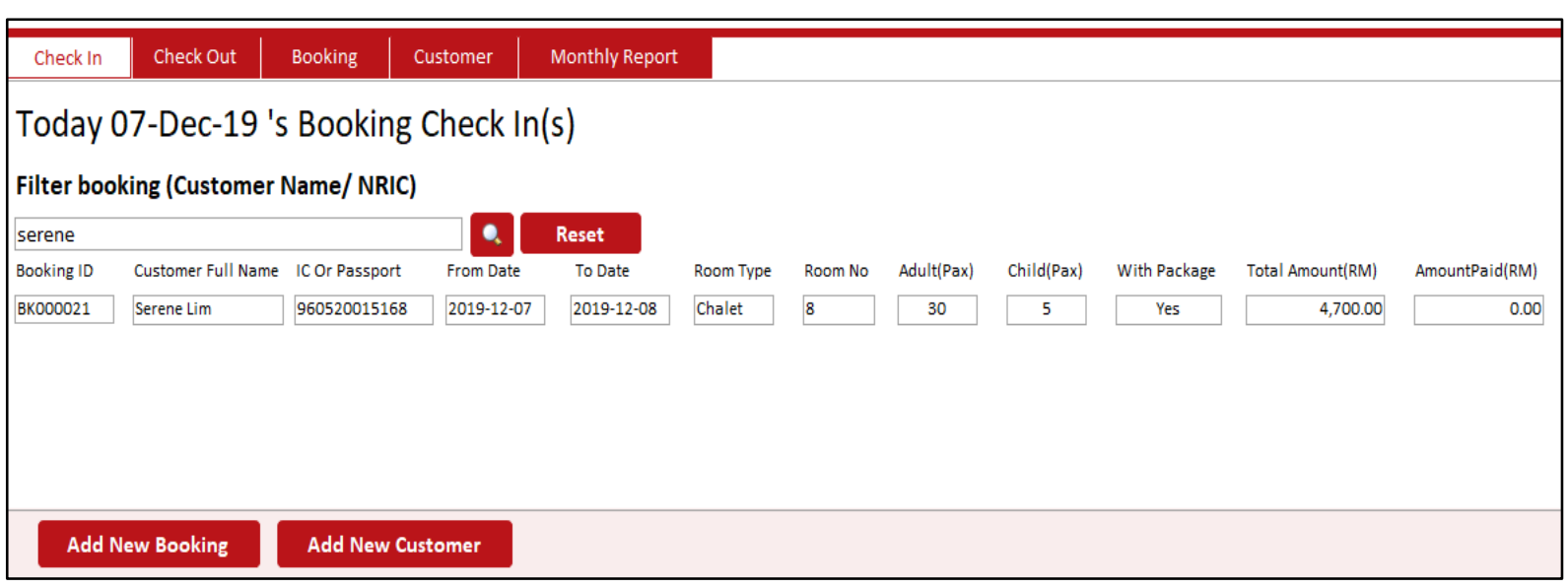

Figure 11. The Search Engine Function to Track Customer Data.

Apart from that, the prototype of Chalet Management System also provides the effectiveness and efficiency for the staff to generate the transaction report. This report provides the total transaction amount for the chalet and hotel within the specified date range as well as monthly. It can assist the manager to analysis the chalet performance and growth and make improvement of each room based on the booking rate. Compared to the current manual system, this report also helps the staff to save a lot of time in tracking the transaction rather than referring to the manual receipt book. Besides that, it is also important for the manager in forecasting the future strategies or expansion of the company. Figure 12 showed the sample of transaction report of ABC Chalet for December 2019.

\begin{tabular}{|c|c|c|c|c|}
\hline \multirow[b]{2}{*}{ Room Type } & \multicolumn{3}{|c|}{$\begin{array}{c}\text { Transaction Report } \\
\text { o1-Dec-19 To 31-Dec-19 }\end{array}$} & \multirow{2}{*}{$\begin{array}{r}\text { 07-Dec-19 } \\
\text { 8:32:46 PM } \\
\text { Total Amount (RM) }\end{array}$} \\
\hline & Room No & Total Booking(s) & Total Guests & \\
\hline Chalet & 6 & 1 & 16 & $4,320.00$ \\
\hline Chalet & 7 & 2 & 20 & $4,200.00$ \\
\hline Chalet & 8 & 1 & 12 & $3,360.00$ \\
\hline Chalet & 10 & 1 & 10 & $2,800.00$ \\
\hline Chalet & 11 & 2 & 75 & $15,400.00$ \\
\hline Hotel & 022 & 1 & 2 & 240.00 \\
\hline Hotel & 024 & 1 & 2 & 240.00 \\
\hline Hotel & 0210 & 1 & 2 & 400.00 \\
\hline Hotel & 0211 & 1 & 2 & 400.00 \\
\hline \multirow[t]{2}{*}{ Hotel } & 0212 & 1 & 2 & 120.00 \\
\hline & & & & $31,480.00$ \\
\hline
\end{tabular}

Figure 12. Transaction Report.

\section{CONCLUSION}

In this study, hospitality firm such as $\mathrm{ABC}$ chalet had been encountering customer dissatisfaction due to their service quality in managing customer especially in the customer check-in process as the reception counter is handled manually with handwritten records. These handwritten records which caused the low data accuracy and efficiency had increased the registration process lead time and led to the poor timeliness of customer service. Thus, high customer satisfaction is not achieved and $\mathrm{ABC}$ chalet was not able to grow. Therefore, a prototype of Chalet Management System was purposed to automate the process of bookings and customer registrations. Customer reservations were registered by this prototype and customer data were recorded by this prototype. Any tracking of records can be done easily with this prototype and this increases the data accuracy and efficiency. It did decrease the registration process lead time and thus improve customer satisfaction. This prototype is ready for production deployment and provides necessary features that are efficient in recording customer's data and enhancing the process in the reception counter. The trial result had also proven that the development of this prototype on helping a hospitality company to deliver a better quality of registration service to the guests and then improve customer satisfaction.

Further study can be made and modification can be done to transform this prototype to an online booking system for customers. For example, this prototype of Chalet Management System can be expanded by the link-up a registration form to the Internet so that it allows the customer to view and choose their preferred room online. As the increasing competitors within the hospitality industry in Pulau Kukup, company which can supply an automated online booking system will have a more competitive advantage compared to others. This also helps to promote the company by using this system as an advertisement to attract more customers and upgrade the image of the company. 


\section{LIMITATION AND RECOMMENDATION}

The limitation of this study is the prototype is not capitalized as much as it just focused on the improving registration process lead time by providing data accuracy and efficiency of the front desk manager in the ABC chalet with digital records for customer bookings and data. Other major factors of customer satisfaction such as the cleanliness of the room and food quality were not taken as part of this study while designing the prototype of this Chalet Management System. This study may miss out the facts that customer satisfaction was low at ABC chalet may due to the poor service quality on these criteria mentioned.

The recommendation for the future study would be the prototype can be expandable not only managing the registration for the customer but also emphasizing the manpower distribution for staffs. A digital timesheet module can be included in the prototype so that the manager of $\mathrm{ABC}$ chalet can forecast the manpower allocation evenly to maintain the cleanliness of the rooms based on the staffs' availability and skillsets from the timesheet. This timesheet module should be accountable for attendance taking as this can also save the time of manager by providing the records of the staffs' clock in and clock out records. Based on these records, the manager can easily manage the staffs and create an appropriate strategy to reward the responsible staffs. These staffs will provide better service quality to the customer and thus improve the customer satisfaction of $\mathrm{ABC}$ chalet.

\section{REFERENCES}

Alsumait, K. (2015). Guests' Waiting Experience at Hotels: Evidence From Saudi Arabia.

Ankur. (2018). Service Quality \& Customer Satisfaction In The Hotel Industry.

Beynon-Davies, P., \& Holmes, S. (2002). Design breakdowns, scenarios and rapid application development. Information and Software Technology, 44(10), 579-592. doi:10.1016/S0950-5849(02)00078-2

Card, A. (2016). The problem with "5 whys." BMJ quality \& safety, 26. doi:10.1136/bmjqs-2016-005849

Chemweno, P., Morag, I., Sheikhalishahi, M., Pintelon, L., Muchiri, P., \& Wakiru, J. (2016). Development of a novel methodology for root cause analysis and selection of maintenance strategy for a thermal power plant: A data exploration approach. EFA, 66, 19-34. doi:10.1016/j.engfailanal.2016.04.001

Chen, D. W., \& Tabari, S. (2017). A Study of Negative Customer Online Reviews and Managerial Responses on Social Media - Case Study of the Marriott Hotel Group in Beijing. Journal of Marketing and Consumer Research, 41(December 2017), 53-64.

Domestic Tourism Performance 2018 - Tourism Malaysia Corporate Site. (2019). Tourism.gov.my.

Fatimah, D. D. S., Supriatna, A. D., \& Kurniawati, R. (2018). Design of personnel information systems using rapid application development method. MATEC Web of Conferences, 197. doi:10.1051/matecconf/201819703016

Guo, G., \& Lu, Y. (2014). Design and realization of hotel management system. Computer Modelling and New Technologies, 18(12), 641-644.

Hassan, M., \& Jalalud, I. (2016). Application of Why-why Analysis to Improve Predictive Maintenance Strategy for Injection Molding Machine. Information Technology Journal, 15, 130-136. doi:10.3923/itj.2016.130.136

Jana, A., \& Chandra, B. (2016). Mediating Role of Customer Satisfaction in the Mid-Market Hotels: An Empirical Analysis. Indian Journal of Science and Technology, 9(1), 1-16. doi:10.17485/ijst/2016/v9i1/81973

Khan, M. Y. H., \& Hossain, A. (2018). The Effect of ICT Application on the Tourism and Hospitality In- dustries in London, 2(4), 60-68. doi:10.21272/sec.4(2).60-68.2018

Martin, J. (1995). Rapid application development. New York, NY, etc.: MacMillan.

Mmutle, T., \& Shonhe, L. (2017). Customers' perception of Service Quality and its impact on reputation in the Hospitality Industry. African Journal of Hospitality, Tourism and Leisure 2223-814X, 6.

Mohd Sallem, N. R., Mohd Nasir, N. E., Wan Mohd Nori, W. M. N., \& Che Ku Kassim, C. K. H. (2017). Small and Medium Enterprises: Critical Problems and Possible Solutions. International Business Management, 11, 47-52. doi:10.3923/ibm.2017.47.52

Mubiri, J. B. (2016). Customer Satisfaction in Hotel Service (Case Lake Kivu Serena Hotel), 47.

Oliver, R. L. (1981). Measurement and evaluation of satisfaction processes in retail settings. Journal of Retailing, 57(3), 25-48.

Watiki, C., \& Chirchir, M. K. (2014). Service Quality and Customer Satisfaction in Hotles in Nairobi, Kenya. 